\title{
European IPF Patient Charter: unmet needs and a call to action for healthcare policymakers
}

\author{
Francesco Bonella ${ }^{1}$, Marlies Wijsenbeek ${ }^{2}$, Maria Molina-Molina ${ }^{3}$, \\ Annette Duck ${ }^{4}$, Rosalba Mele ${ }^{5}$, Klaus Geissler $^{6}$ and Wim Wuyts ${ }^{7}$
}

Affiliations: ${ }^{1}$ Ruhrlandklinik, Westdeutsches Lungenzentrum am Universitätsklinikum Essen gGmBH, Essen, Germany. ${ }^{2}$ Dept of Pulmonary Medicine, Erasmus Medical Centre, University Hospital, Rotterdam, The Netherlands. ${ }^{3}$ ILD Unit, Dept of Respiratory Medicine, University Hospital of Bellvitge, Institut d'Investigacions Biomèdiques de Bellvitge, Barcelona, and Centro de Investigaciones Biomédicas en Red de Enfermedades Respiratorias (CIBERES), Spain. ${ }^{4}$ Independent ILD-Specialist Nurse, Manchester, UK. ${ }^{5}$ AMA Fuori Dal Buio, Modena, Italy. ${ }^{6}$ Lungenfibrose eV, Essen, Germany. ${ }^{7}$ Dept of Respiratory Medicine, Unit for ILD, University Hospital Leuven, Leuven, Belgium.

Correspondence: Francesco Bonella, Ruhrlandklinik, Westdeutsches Lungenzentrum am Universitätsklinikum Essen gGmBH, Tüschener Weg 40, 45239 Essen, Germany.

E-mail: francesco.bonelladruhrlandklinik.uk-essen.de

ABSTRACT Patient advocacy groups play an important role in supporting patients with chronic diseases and promoting better care. The aim of this patient-physician initiative was to gather perceptions from European idiopathic pulmonary fibrosis (IPF) patient advocacy groups regarding inequalities and unmet needs in IPF care, in order to develop a Patient Charter to advocate for better care.

In total, 11 European patient advocacy groups were interviewed regarding the care of patients with IPF in their countries. Interview feedback was presented to a Working Group including patient advocacy group representatives and IPF specialists; key areas of agreement were developed into the European IPF Patient Charter.

The interviews identified five key themes that fed into the final Charter: the need for improved diagnosis, treatment access, holistic care, disease awareness and palliative care. The final Charter was endorsed by patient advocacy groups and presented to 26 Members of the European Parliament in September 2014. It has received $>8900$ signatures to date.

This patient-physician initiative highlights the inequalities and unmet needs in IPF care across Europe, and demonstrates how this insight can inform the development of a Patient Charter, designed as a call to action for healthcare policymakers to drive improvement in European IPF care.

@ERSpublications

European IPF Patient Charter details unmet needs in IPF and presents a call to action for healthcare policymakers http://ow.ly/Td8rj

For editorial comment see Eur Respir J 2016; 47: 403-405 [DOI: 10.1183/13993003.01902-2015].

This article has supplementary material available from erj.ersjournals.com

Received: Dec 162014 | Accepted after revision: Sept 202015 | First published online: Nov 192015

Support statement: This project was facilitated by Weber Shandwick, an international healthcare consultancy, funded through an unrestricted grant from InterMune International AG, which became a wholly owned subsidiary of F. Hoffmann-La Roche Ltd in 2014. InterMune International AG had no influence on the set up of the European IPF Patient Charter or in the interpretation of the statements included in the final Charter. Funding information for this article has been deposited with FundRef.

Conflict of interest: Disclosures can be found alongside the online version of this article at erj.ersjournals.com

Copyright CERS 2016 


\section{Introduction}

Idiopathic pulmonary fibrosis (IPF) is a progressive, irreversible, chronic and ultimately fatal rare interstitial lung disease (ILD) [1,2]. The prevalence of IPF in Europe is reported to range from three to nine cases per 100000 population [3] and life expectancy for patients with the disease is 2-5 years following diagnosis [4].

Lung transplantation may offer an effective treatment option for a small number of suitable patients with IPF $[5,6]$. Other nonpharmacological treatments include supplemental oxygen, pulmonary rehabilitation, antireflux therapy and palliative care [1]. Two pharmacological antifibrotic treatments, i.e. pirfenidone and nintedanib, approved in Europe in 2011 [7, 8] and 2015 [9, 10], respectively, have been shown to significantly reduce the decline in lung function $[1,7,9,11]$

With the advent of pharmacological treatment options that slow disease progression, it is more important than ever that patients with IPF are diagnosed quickly and have access to the required care $[7,9,11]$. However, unfortunately, access to IPF care across Europe is not homogeneous and it may take several years before a centrally approved treatment is available to all patients. Patient advocacy groups (PGs) play an important role in supporting patients with chronic diseases and advocating for better care [12, 13], and have helped to develop patient charters in other diseases that set out the basic rights of patients and aim to improve care by bringing unmet needs to the attention of national healthcare policymakers $[14,15]$.

Here, we report findings of a patient-physician initiative involving the perceptions of PGs from nine European countries regarding the inequalities and unmet needs in European IPF care. The development of this work into the European IPF Patient Charter, describing the rights of patients with IPF and a call to action for European policymakers and healthcare providers, is also described.

\section{Methods}

Questionnaire and interviews

European PGs from nine countries worked with an external healthcare consultancy to develop a questionnaire to elicit feedback on issues affecting the diagnosis, management and care of patients with IPF in Europe (figure 1 and table 1). Patients were consulted throughout this process via the PGs. In addition to an English version, the questionnaire was translated into Dutch, French, German, Italian and Spanish. Board members of each PG met to discuss the questionnaire and proposed feedback for their country, and then a representative board member(s) from each PG was interviewed by telephone on a 1:1 basis by the external healthcare consultancy for $\sim 1 \mathrm{~h}$ using the questionnaire. Responses were transcribed verbatim, analysed and consolidated by the external healthcare consultancy.

\section{Working Group meeting}

Common themes and challenges highlighted in the interviews were presented at a 2-day Working Group meeting in March 2014, in Brussels, Belgium, attended by PG representatives and IPF healthcare professional (HCP) specialists invited by the PGs on the basis of long-term collaborations (online supplementary table S1). Five HCPs (four physicians and one specialist nurse) participated in discussions to provide medical input and to help PGs understand the medical challenges associated with IPF in their countries; they did not direct discussions. The meeting comprised various plenary and breakout sessions (online supplementary table S2). Translators were present to enable participants of all nationalities to partake in discussions, and the meeting was facilitated, video-recorded and transcribed by the external healthcare consultancy, with participants' consent. Consolidated feedback from the PG interviews was presented to the Working Group in slide format and, following a discussion of each point, key areas of agreement were summarised into a framework for the European IPF Patient Charter.

\section{European IPF Patient Charter}

The framework of the Charter was expanded and revised through two rounds of electronic comments from the PGs following the Working Group meeting, and the final draft of the European IPF Patient Charter was endorsed at a meeting of PGs in May 2014 in Berlin, Germany.

\section{Results}

\section{Participants}

Interviews were conducted with 12 PG representatives from 11 PGs in nine European countries (Austria, Belgium, France, Germany, Ireland, Italy, Spain, The Netherlands and UK; table 2). All of the PG representatives interviewed had extensive experience with IPF advocacy and six had personal experience of IPF (three had IPF and three had cared for a spouse or parent with IPF; table 2). A total of 16 participants attended the Working Group meeting to discuss feedback from the interviews (table 2 and online supplementary table S1). Consolidated feedback from the interviews with PGs is reported in table 3. 
Representatives from 11 European PGs\# work with an external healthcare consultancy? to develop a questionnaire on the diagnosis, management and care of patients with IPF in Europe (November 2013)

Interviews with PG representatives are conducted by an external healthcare consultancy using the questionnaire (January-March 2014)

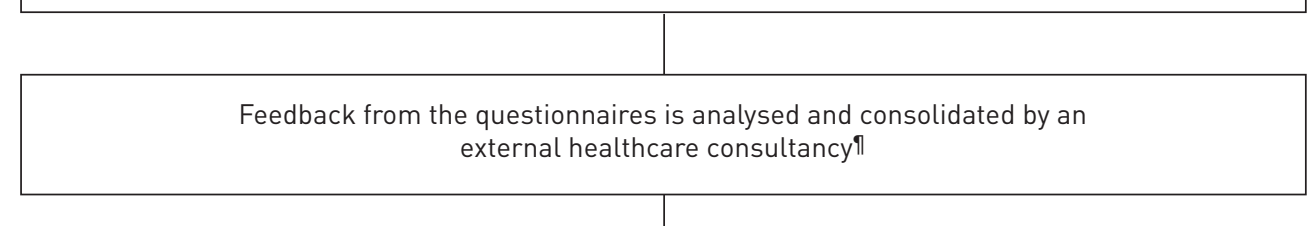

Common themes and challenges highlighted in the interviews are presented at a 2-day Working Group meeting, attended by PG representatives and HCPs specialised in IPF (March 2014)+

Key areas of agreement are discussed by the Working Group and consolidated into a framework for the European IPF Patient Charter by an external healthcare consultancy?

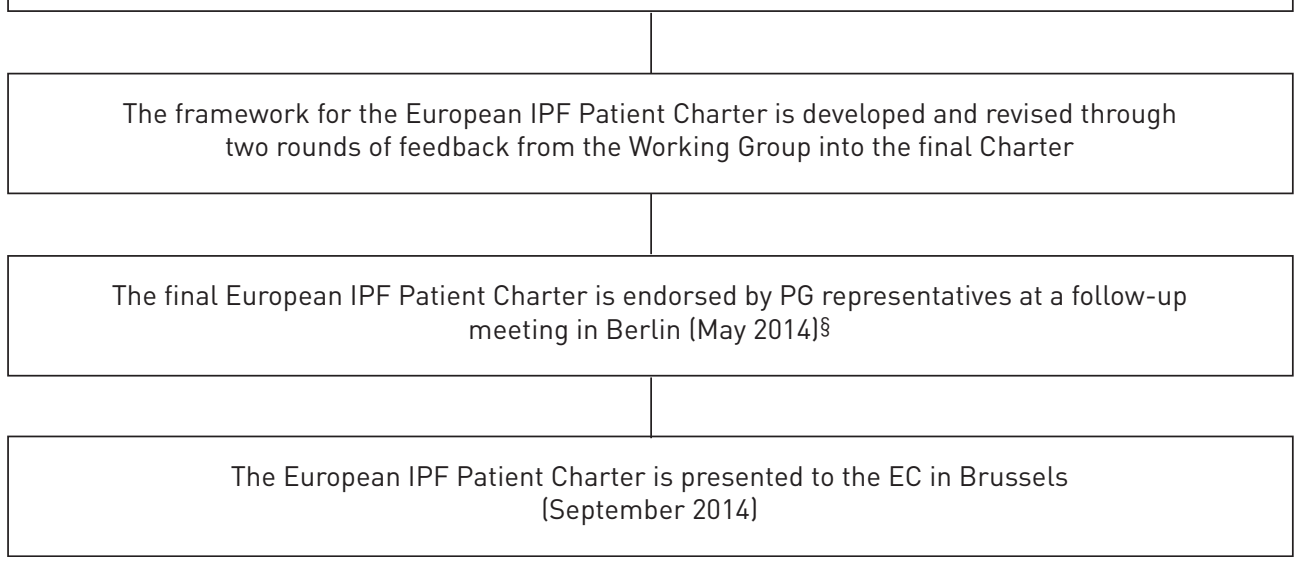

FIGURE 1 Development process for the European IPF Patient Charter. PG, patient advocacy group; IPF: idiopathic pulmonary fibrosis; HCP: healthcare professional; EC: European Commission. \#: LOT mit Lungenfibrose Forum-Austria (Austria), Belgische Vereniging voor Longfibrose VZW (Belgium), Association pour la fibrose pulmonaire (France), Lungenfibrose eV (Germany), Irish Lung Fibrosis Association (Ireland), AMA Fuori Dal Buio (Italy). Asociación de Familiares y Enfermos de Fibrosis Pulmonar Idiopática (AFEFPI) (Spain), Longfibrose Patiëntenvereniging (The Netherlands), Longfonds (The Netherlands), Action for Pulmonary Fibrosis (UK) and British Lung Foundation (UK); ๆ: Weber Shandwick; ${ }^{+}$: participants in the Working Group meeting are provided in online supplementary table S2; ${ }^{\S}$ : representatives from all of the PGs involved in the development of the European IPF Patient Charter attended this meeting, with the exception of representatives from Belgium and The Netherlands, who endorsed the Charter in writing.

\section{Feedback from interviews regarding diagnosis}

All PGs reported problems with the diagnosis of IPF in their country. A lack of familiarity with IPF by general practitioners (GPs) was identified as a major problem that led to delayed diagnosis in almost every country, e.g. the Spanish PG reported that Spanish GPs may see only one or two patients with IPF every 5 years.

The missing link for patients is the lack of information among the GPs. They are not informed about the disease and, in turn, they cannot properly advise patients or refer them to the right specialists.

PG representative, France

Furthermore, eight PGs reported that misdiagnosis was a common problem in IPF, with patients often initially receiving treatment for a different respiratory disorder. Given their front-line role, the tendency for misdiagnosis among GPs meant that the referral of patients to centres of expertise was often delayed. 
One of the major issues patients face is that they often receive a false diagnosis.

PG representative, The Netherlands

PGs reported that they believed diagnosis of IPF proceeded more rapidly following referral to specialist pulmonology clinics. However, they reported a lack of sufficient pulmonology specialists or accessible specialist care clinics. Furthermore, despite the specialist nature of these clinics, PGs perceived a lack of familiarity with IPF among some pulmonology specialists, including misconceptions about diagnosis and management of IPF, and a lack of awareness for clinical guidelines for diagnosis, despite the availability of national guidelines for IPF in most European countries.

Germany formed guidelines [for IPF] in 2013 for all doctors to follow, but unfortunately this is not always the case.

PG representative, Germany

Access to diagnostic testing was reported to be variable, with a lack of priority access to high-resolution computed tomography for patients with suspected IPF reported by two PGs. The Italian PG reported that patients were responsible for paying for some or all of their diagnostic testing.

TABLE 1 Questionnaire developed by patient advocacy groups (PGs) and external healthcare consultancy (Weber Shandwick), and used to conduct PG interviews

\section{Questions asked}

\section{Information about IPF}

1. Do healthcare providers (e.g. the NHS) suggest websites/information to learn more about IPF?

2. Does your association provide information about IPF to patients?

3. Is information on new therapies made available for patients?

4. Are there any other support groups in your country and, if so, do you collaborate with them and how?

\section{From diagnosis to treatment}

1. What are the problems that patients face during their IPF journey (until they get a diagnosis) in your country?

2. What are the problems that patients face during their IPF journey (until they receive treatment) in your country?

3. What are the conditions to apply for a lung transplant?

4. Is it correct that there is a lung transplantation registry in your country?

5. How is the lung transplantation registry managed?

6. Do treating institutions (hospital, centre of expertise) offer rehabilitation classes for patients with IPF and their carers?

7. Is palliative care included in the treatment for end-of-life IPF patients?

\section{Reimbursement and research}

1. Is pharmacological treatment for IPF reimbursed in your country?

2. Is it entirely reimbursed by health services?

3. Do you know if IPF is a priority on the rare disease agenda in your country?

4. Are there government funds dedicated to IPF research?

\section{Obstacles/opportunities}

1. What are the current issues/barriers in IPF in your country?

2. Which of the above would you consider a priority?

3. What solutions can be adopted to address the current gaps?

4. Are you aware of existing best practices in other countries?

\section{EU IPF Charter}

1. Do you agree that there is a need for an EU IPF Charter? Why?

2. What would be your expectations for an EU IPF Charter (more policy weight, impact on medical guidelines, common voice for IPF, focusing action, etc.)?

3. What are the five key themes that you would like to see in the EU IPF Charter?

4. Are you aware of the existence of the UK Charter on IPF? Do you think that the UK Patient Charter is a good starting point for the European one?

5. Do you think that the endorsement of European policymakers could be an asset?

6. Would you be interested in potentially playing an active role in the development process?

NHS: National Health Service (UK); IPF: idiopathic pulmonary fibrosis; EU: European Union. 
TABLE 2 Patient advocacy groups (PGs) involved in the development of the European IPF Patient Charter

\begin{tabular}{|c|c|c|c|c|c|}
\hline PG & Country & $\begin{array}{l}\text { Date of } \\
\text { foundation }\end{array}$ & Website & $\begin{array}{l}\text { No. of } \\
\text { representatives } \\
\text { interviewed }\end{array}$ & $\begin{array}{l}\text { No. of } \\
\text { representatives at } \\
\text { Working Group } \\
\text { meeting }\end{array}$ \\
\hline $\begin{array}{l}\text { LOT mit Lungenfibrose } \\
\text { Forum-Austria }\end{array}$ & Austria & $2009^{\#}$ & www.lungenfibroseforum.at & \multicolumn{2}{|c|}{1 male patient with IPF } \\
\hline $\begin{array}{l}\text { Belgische Vereniging voor } \\
\text { Longfibrose VZW }\end{array}$ & Belgium & 2010 & www.longfibrose.org & \multicolumn{2}{|c|}{$\begin{array}{l}1 \text { male patient with IPF, } \\
\text { lung transplant in } 2010\end{array}$} \\
\hline Lungenfibrose eV & Germany & 2012 & www.lungenfibrose.de & \multicolumn{2}{|c|}{$\begin{array}{c}1 \text { female with non-IPF } \\
\text { lung fibrosis }\end{array}$} \\
\hline $\begin{array}{l}\text { Irish Lung Fibrosis } \\
\text { Association }\end{array}$ & Ireland & 2002 & www.ilfa.ie & $\begin{array}{c}2 \text { females, both } \\
\text { previously cared for } \\
\text { a spouse/parent } \\
\text { with IPF }\end{array}$ & $\begin{array}{c}1 \text { female, previously } \\
\text { cared for a spouse } \\
\text { with IPF }\end{array}$ \\
\hline $\begin{array}{l}\text { Action for Pulmonary } \\
\text { Fibrosis }\end{array}$ & UK & 2013 & www.actionpulmonaryfibrosis.org & \multicolumn{2}{|c|}{$\begin{array}{l}1 \text { male patient with IPF, } \\
\text { lung transplant in } 2005\end{array}$} \\
\hline British Lung Foundation & UK & 1984 & www.blf.org.uk & \multicolumn{2}{|c|}{1 male } \\
\hline $\begin{array}{l}\text { Longfibrose } \\
\quad \text { Patiëntenvereniging" }\end{array}$ & Netherlands & 2001 & www.longfibrose.nl & \multicolumn{2}{|c|}{1 female } \\
\hline Longfonds ${ }^{\pi}$ & Netherlands & 1959 & www.longfonds.nl & \multicolumn{2}{|c|}{1 female } \\
\hline
\end{tabular}

IPF: idiopathic pulmonary fibrosis; NA: not applicable. " : LOT was formed in 2009, LOT mit Lungenfibrose was formed in 2015; ": the same participant represented both the Longfibrose Patiëntenvereniging and Longfonds PG organisations.

\section{Feedback from interviews regarding access to treatment}

Six PGs reported unequal access to IPF treatment in their country, including supplementary oxygen, lung transplantation, pulmonary rehabilitation and pharmacological therapy. In Spain, contracts to supply supplementary oxygen were often executed by third parties with little sensitivity towards those patients most in need; and in Belgium, access to supplementary oxygen had been affected by budget cuts meaning that those patients most in need did not always have access to this vital treatment.

On most occasions there is no sensitivity towards patients that require oxygen to survive. The bureaucracy behind the process is a major obstacle and there is no sense of priority for the provision of oxygen to patients.

PG representative, Spain

Lung transplant registries were reported to operate largely on a national basis and most PGs felt this worked well. However, restrictions in most countries meant that lung transplantation was subject to age restrictions (under 65 years and, in some centres, under 60 years), which excluded many potentially suitable patients. Waiting times to receive transplantations were often 10 months or more. In contrast, UK lung transplant services operated on a regional basis, each with their own criteria for qualification. There was a perception by a UK PG representative that there was little understanding of the rapidly progressive nature of IPF in relation to transplant list waiting times, compared with other lung diseases.

As there is no national transplant waiting list, it is not guaranteed that the person who needs the transplant most will get an available organ first.

PG representative, UK

Six PGs reported the availability of pulmonary rehabilitation classes in their country; however, these classes were not necessarily tailored to the needs of a patient with IPF. Furthermore, these classes provided no support to the patient's carer/family and they were often in locations that were too challenging to access (e.g. too many stairs) or too far away for a patient with severe breathlessness. 
TABLE 3 Feedback from interviews with patient advocacy group representatives

\section{Feedback regarding the diagnosis of IPF}

- HCPs, including GPs, radiologists, pathologists and pulmonologists, lack awareness of IPF and how to diagnose it

- False diagnoses with other respiratory disorders are common

- Awareness of IPF guidelines is often poor and access to diagnostic testing is not always straightforward

- Referral to specialists is often significantly delayed

Feedback regarding access to treatment

- Supplementary oxygen is not always available to those most in need

- Age restrictions for lung transplantations exclude many healthy, viable patients

- Pulmonary rehabilitation is not always available or easily accessed by patients

- Reimbursement for treatment is limited in some countries

- The availability of pirfenidone is limited in some countries

Feedback regarding holistic care

- Multidisciplinary care teams comprising of radiologists, pulmonologists, specialist nurses and physiotherapists are lacking

- Emotional and psychological support for patients with IPF and their families is insufficient

\section{Feedback regarding the availability of information on IPF}

- Lack of knowledge among HCPs regarding IPF directly impacts the knowledge and understanding of patients

- Patients with IPF lack sufficient information on the disease and what treatments are available

- PGs play a huge role in providing disease and treatment information to patients with IPF

- Greater awareness of IPF as a chronic, debilitating and lethal disease is required among the general public

- The status of IPF as a rare disease is under-recognised by policymakers and healthcare bodies, hindering the availability of funding for IPF research and centres of excellence

\section{Feedback regarding palliative care}

- Palliative care for patients is not always available

- The quality of palliative offered to patients with IPF is highly variable and does not always address the specific needs of a patient with IPF

IPF: idiopathic pulmonary fibrosis; HCP: healthcare professional; GP: general practitioner.

Reimbursement for IPF treatment was available in all of the countries represented by the PGs; however, there were limitations on the degree of reimbursement in Austria, Ireland, Italy and Spain. Furthermore, in France, bureaucracy sometimes made it difficult to obtain reimbursement, with patients often struggling to get GPs to complete the necessary forms. At the time of the interviews, pirfenidone was the only approved treatment for IPF in Europe; however, it was not always available to patients, including in Spain and certain regions of Italy. Furthermore, a successful public campaign was required in Ireland in order to get pirfenidone reimbursement for patients. PGs often acted as a source of support to patients in identifying and exercising their medical and financial rights.

This has been a battle. When pirfenidone was approved, the Irish Lung Fibrosis Association organised a media campaign in order to get the drug reimbursed.

$$
\text { PG representative, Ireland }
$$

\section{Feedback from interviews regarding holistic care}

Five PGs reported the need for a multidisciplinary team to facilitate the diagnosis and management of patients with IPF, including radiologists, ILD specialists and specialist nurses. The need for physiotherapists to be part of the multidisciplinary team was also highlighted. The Belgian PG recommended that patients and their families should have one point of contact, e.g. a specialist nurse, who was there to support the wider medical team and to coordinate patient care.

The lack of multidisciplinary team plays a role here. For instance, physiotherapy is not contemplated as part of the process. The multidisciplinary team should not only include lung specialists, radiologists and pathologists, it should also include physiotherapists. 
Three PGs reported a lack of routine counselling/psychological support services for patients with IPF, and stressed the need to provide adequate emotional support to carers and families, particularly leading up to, and following, the death of a patient. Where available, pulmonary rehabilitation classes were reported to be an enormous source of emotional support to patients with IPF; however, the availability and accessibility of such classes varied widely by country.

These [pulmonary rehabilitation] courses are of great importance to patients. Not only physically, but also socially and mentally to cope with IPF and find support with each other. This is really missing at this point.

PG representative, Belgium

PGs reported that their organisations often played a large role in providing emotional support to patients. For example, in Italy where patients often travelled large distances to share their stories with the PG; or in the UK where the PG was establishing a network of support groups; or in Germany where the PG had established support groups and a telephone helpline for patients.

\section{Feedback from interviews regarding availability of information on IPF}

Six PGs reported that HCPs failed to provide patients with suitable sources of information on IPF at diagnosis and in more than one instance it was reported that patients had been provided with nothing other than a terminal diagnosis. There was a strong perception among the PGs that this needed to change and that HCPs, including GPs and specialists, needed to be better informed about IPF and equipped with the necessary information to communicate with patients in a sensitive manner.

Some patients say they were given little information at the time of diagnosis and it was suggested that they could look on the internet. Others have said that they were told the good news is you don't have cancer.

PG representative, UK

PGs also reported a lack of suitable information for patients regarding other aspects of IPF, including treatment, comorbidities and palliative care. While information on new pharmacological therapies for IPF was available in most countries, this was often perceived to be insufficient and much of the information online was reported to be irrelevant or incorrect. One of the UK PG representatives suggested that information on new therapies for IPF should be communicated to patients directly by their specialist.

In the absence of appropriate information for patients with IPF, nearly all of the PGs had taken on the role of providing disease information to patients. For example, the German PG provided a telephone support line, website, information leaflet, workshops and list of useful contact information; the Austrian, Italian and UK PGs provided a website and information booklet on IPF; the Italian PG provided educational videos; and the French PG provided a booklet on IPF and assistance with referral to specialist care. However, the Spanish PG only had sufficient funding to provide a small website with basic information.

PG representatives perceived a lack of awareness of IPF amongst the general public and emphasised the need for awareness campaigns, detailing the chronic and debilitating nature of IPF, and its mortality. In all countries except Germany and The Netherlands, the status of IPF as a rare disease is not entirely recognised, thereby limiting disease awareness and funding. PG representatives stressed the need for additional research funding and the need to promote strong networks of IPF experts and centres of excellence as key priorities.

\section{Feedback from interviews regarding palliative care}

Six PGs reported the availability of palliative care for patients with IPF in their countries; however, the degree of availability was often highly variable. For example, in Italy, where palliative care was planned at a national level, which did not translate successfully on a regional basis; and in Spain, where there was no IPF-specific protocol to be followed for palliative care. Furthermore, in Belgium, palliative care was often not even discussed, as it is considered a taboo subject. The UK PG representative reported that although IPF-specific palliative care was addressed in national guidelines, supporting the need for palliative care to begin from the day of diagnosis, not just towards the end of life, adherence to this guidance was inconsistent [16].

\section{Working Group meeting and development of the European IPF Patient Charter}

The Working Group meeting agenda and participant list are provided in online supplementary tables S1 and S2. The final European IPF Patient Charter is provided in table 4 [17]. 
TABLE 4 The European IPF Patient Charter developed following the Working Group meeting

Patients with IPF and their families should have fair and consistent rights to:

- Early and accurate diagnosis, by raising awareness of IPF and recognising IPF as a chronic condition

- Equal access to care, including medication and transplantation, irrespective of age, by coordinating timely and efficient drug approvals at a national level and revising the eligibility criteria for lung transplantation

- A holistic approach to standardise IPF management, by involving all aspects of support from early diagnosis to treatment and rehabilitation including correct referral, access to multidisciplinary teams, lung transplantation, emotional support, ambulatory and domiciliary services

- Comprehensive and high-quality information about IPF, including its treatment, transplant information and emotional care for both patients and families

- Better access to palliative care and end-of-life care, with support for both patients and their families

IPF: idiopathic pulmonary fibrosis.

\section{Discussion}

To the best of our knowledge, this is the first report of a PG-centred initiative aimed at identifying unmet needs in IPF and consolidating these in a Patient Charter. In this initiative, systematic interviews with 12 PG representatives from nine European countries identified a number of unmet needs in IPF, which formed the basis of the European IPF Patient Charter. Similar needs have been identified in other studies in IPF. For example, the difficulties faced by HCPs in reliably diagnosing IPF [13, 18-20], the need for improved multidisciplinary care [21-23], the need for improved access to treatment [24], the need for improved awareness of clinical guidelines [18, 25] and the need for improved palliative care [26]. This initiative also emphasised the need for improved disease awareness and information, consistent with two recent PG-informed reports from the British Lung Foundation [14, 27, 28]. However, important differences in unmet needs between countries were also identified, including inequalities in the availability of treatments and pulmonary rehabilitation classes, and in the degree of financial support available to patients.

Involving patients' organisations in consensus statements or task forces has become indispensable, especially for rare and orphan diseases $[29,30]$, and patients' initiatives are essential to inform future clinical research, reveal structural problems in standards of care, gain political attention and ensure that goals are reflective of patients' needs, leading to improved outcomes [12-15, 29, 31, 32]. Patient charters can help to drive improvement in a disease area by identifying and addressing gaps in existing care, urging policymakers to improve access to, and quality of, care, and supporting improvements in clinical practice [33].

The European IPF Patient Charter provides information about unmet needs in IPF care for national governments, European institutions and healthcare organisations that, if adopted, would ensure improvements in the standard of care and patients' quality of life, while supporting efforts to develop better long-term treatments and disease awareness among HCPs and the general public [17]. The European IPF Patient Charter was presented at a round-table meeting of PG representatives and Members of the European Parliament (MEPs) in September 2014 in Brussels, Belgium. Additional 1:1 meetings between individual PGs and MEPs were conducted immediately before and after the round-table meeting. In total, $26 \mathrm{MEPs}$ from nine European countries heard the messages of the Charter and its call to action. These meetings resulted in a letter signed by MEPs advising that the European IPF Patient Charter be shared with national health authorities across Europe and with national representatives sitting on the European Commission Expert Group on Rare Diseases. This letter was also shared at a Joint Meeting of the European Chief Medical, Dental and Nursing Officers, held on October 6-7, in Rome, Italy, which is regarded as a platform for sharing best practice in Europe.

While the impact of these initiatives on healthcare policy is yet to be fully realised, similar charters developed in collaboration with PGs have succeeded in raising the profile of diseases. For example, national organisations and governments are now invited to adopt the European Heart Health Charter in order to promote cardiovascular health across Europe [14]; and the Psoriasis Mandate, detailing five key rights of patients with psoriasis (not considered a rare disease), has received >19000 signatures of support [15].

The IPF Charter is available in English, Dutch, French, German, Italian and Spanish, and has been publicised by each PG organisation within their country. Less than 10 months after it was launched, $>8900$ individuals have pledged their support (electronically or via collection of handwritten signatures) for the European IPF Patient Charter, indicating the level of awareness that has already been achieved across Europe for the Charter and its messages [17]. However, there is still a long way to go given the estimated prevalence of IPF in Europe of between 15000 and 45000 patients [3], and collaboration between countries and PG organisations is crucial to further raise awareness of the inequalities in care and unmet needs of patients with IPF. 
This patient-physician initiative should be considered in light of some limitations. First, the findings reflect PG observations and, while efforts have been made to verify all facts and figures, consideration should be given to the nature of these perceptions when interpreting them. Second, although direct patient involvement was limited, all participants were representing national PGs and were able to comment beyond their personal experiences to draw upon the issues affecting all patients with IPF in their country. Nevertheless, patients were also consulted by PGs during development of the questionnaire and the Charter. Third, the Charter may not be entirely representative of the situation across all of Europe as many European countries were not involved, especially those in Eastern Europe. PGs for lung fibrosis are not well established in this region, emphasising the lack of support available to patients in certain countries and the need for a pan-European initiative to address the unmet needs of all European patients with IPF.

\section{Conclusion}

This patient-physician initiative highlights the inequalities in IPF care across Europe and the need to more adequately support, care and inform patients with this devastating disorder, and their families. It also demonstrates how insight from PGs, representing the voice and experience of many patients in a country, can be used to highlight unmet needs in a rare disease such as IPF and inform the development of a Patient Charter. While the impact of the European IPF Patient Charter on healthcare policymakers to drive improvement in IPF care remains to be seen, the awareness that has been raised through pledged signatures is an excellent first step in raising the profile of this disease.

\section{Acknowledgements}

The authors would like to thank all the PG representatives and organisations who participated in this initiative, including: Günther Wanke (LOT mit Lungenfibrose Forum-Austria, Austria); The Belgische Vereniging voor Longfibrose VZW, Belgium; Francois Enjalran (Association pour la fibrose pulmonaire, France); Dagmar Kauschka (Lungenfibrose eV, Germany); Claire Tunissen and Nicola Cassidy (Irish Lung Fibrosis Association, Ireland); Daniela Magnani (AMA Fuori Dal Buio, Italy); Ruth Cordova Martin and Carlos Lines Millan (Asociación de Familiares y Enfermos de Fibrosis Pulmonar Idiopática (AFEFPI), Spain); Mike Bray (Action for Pulmonary Fibrosis, UK); Steven Wibberley (British Lung Foundation, UK); and Lida Naber (Longfibrose Patiëntenvereniging, The Netherlands and Longfonds, The Netherlands).

The authors would also like to thank AMA Fuori Dal Buio, Italy for creation of a website portal through which the European IPF Patient Charter could be downloaded in six different languages and signed; and for providing the Charter in six different languages for presentation to the European Parliament.

Medical writing support was provided by Lauren Donaldson, on behalf of Complete Medical Communications Ltd, funded by F. Hoffmann-La Roche Ltd.

Patient advocacy groups involved in the development of the European IPF Patient Charter: LOT mit Lungenfibrose Forum-Austria, Austria; Belgische Vereniging voor Longfibrose VZW, Belgium; Association pour la fibrose pulmonaire, France; Lungenfibrose eV, Germany; Irish Lung Fibrosis Association, Ireland; AMA Fuori Dal Buio, Italy; Asociación de Familiares y Enfermos de Fibrosis Pulmonar Idiopática (AFEFPI), Spain; Action for Pulmonary Fibrosis, UK; British Lung Foundation, UK; Longfibrose Patiëntenvereniging, The Netherlands; and Longfonds, The Netherlands.

F. Bonella is secretary of the European Respiratory Society Diffuse Lung Parenchymal Disease (DLPD) Group (1.5).

\section{References}

1 Raghu G, Rochwerg B, Zhang Y, et al. An official ATS/ERS/JRS/ALAT clinical practice guideline: treatment of idiopathic pulmonary fibrosis. Am J Respir Crit Care Med 2015; 192: e3-e19.

2 Schoenheit G, Becattelli I, Cohen AH. Living with idiopathic pulmonary fibrosis: an in-depth qualitative survey of European patients. Chron Respir Dis 2011; 8: 225-231.

3 Hutchinson J, Fogarty A, Hubbard R, et al. Global incidence and mortality of idiopathic pulmonary fibrosis: a systematic review. Eur Respir J 2015; 46: 795-806.

$4 \quad$ Meltzer EB, Noble PW. Idiopathic pulmonary fibrosis. Orphanet J Rare Dis 2008; 3: 8.

5 Orens JB, Estenne M, Arcasoy S, et al. International guidelines for the selection of lung transplant candidates: 2006 update - a consensus report from the Pulmonary Scientific Council of the International Society for Heart and Lung Transplantation. J Heart Lung Transplant 2006; 25: 745-755.

6 Kistler KD, Nalysnyk L, Rotella P, et al. Lung transplantation in idiopathic pulmonary fibrosis: a systematic review of the literature. BMC Pulm Med 2014; 14: 139.

7 Noble PW, Albera C, Bradford WZ, et al. Pirfenidone in patients with idiopathic pulmonary fibrosis (CAPACITY): two randomised trials. Lancet 2011;377: 1760-1769.

8 European Medicines Agency. European public assessment report for Esbriet ${ }^{\oplus}$ pirfenidone. www.ema.europa.eu/ema/ index.jsp?curl=pages/medicines/human/medicines/002154/human_med_001417.jsp\&mid=WC0b01ac058001d124 Date last updated: March 6, 2015. Date last accessed: July 14, 2015.

9 Richeldi L, du Bois RM, Raghu G, et al. Efficacy and safety of nintedanib in idiopathic pulmonary fibrosis. $N$ Engl J Med 2014; 370: 2071-2082.

10 European Medicines Agency. EU/3/13/1123: Public summary of opinion on orphan designation: Nintedanib for the treatment of idiopathic pulmonary fibrosis. www.ema.europa.eu/ema/index.jsp?curl=pages/medicines/human/ orphans/2013/05/human_orphan_001201.jsp\&mid=WC0b01ac058001d12b Date last updated: March 12, 2015. Date last accessed: July 14, 2015. 
11 King TE Jr, Bradford WZ, Castro-Bernardini S, et al. A phase 3 trial of pirfenidone in patients with idiopathic pulmonary fibrosis. N Engl J Med 2014; 370: 2083-2092.

12 European Respiratory Society. Patient organisations and the European Lung Foundation. European Lung white book. Sheffield, European Respiratory Society, 2015; pp. 432-439.

13 Spagnolo P, du Bois RM, Cottin V. Rare lung disease and orphan drug development. Lancet Respir Med 2013; 1: 479-487.

14 European Heart Health Charter. Mortality and morbidity. www.heartcharter.org/read-charter/default.aspx Date last updated: 2015. Date last accessed: July 14, 2015.

15 Psoriasis 360. The Psoriasis Mandate. http://psoriasis360.com/psoriasis-mandate Date last updated: 2015. Date last accessed: July 14, 2015.

16 National Clinical Guideline Centre (UK). Diagnosis and management of suspected idiopathic pulmonary fibrosis: idiopathic pulmonary fibrosis. www.nice.org.uk/guidance/cg163 Date last updated: June 2013. Date last accessed: July 14, 2015.

17 IPF World. European IPF Patient Charter. www.ipfcharter.org/the-charter/ Date last updated: 2015. Date last accessed: July 14, 2015.

18 Wells AU. Managing diagnostic procedures in idiopathic pulmonary fibrosis. Eur Respir Rev 2013; 22: 158-162.

19 Cottin V. Current approaches to the diagnosis and treatment of idiopathic pulmonary fibrosis in Europe: the AIR survey. Eur Respir Rev 2014; 23: 225-230.

20 Duck A, Spencer LG, Bailey S, et al. Perceptions, experiences and needs of patients with idiopathic pulmonary fibrosis. J Adv Nurs 2015; 71: 1055-1065.

21 Tomassetti S, Piciucchi S, Tantalocco P, et al. The multidisciplinary approach in the diagnosis of idiopathic pulmonary fibrosis: a patient case-based review. Eur Respir Rev 2015; 24: 69-77.

22 du Bois RM. An earlier and more confident diagnosis of idiopathic pulmonary fibrosis. Eur Respir Rev 2012; 21 : 141-146.

23 Oldham JM, Noth I. Idiopathic pulmonary fibrosis: early detection and referral. Respir Med 2014; 108: 819-829.

24 Riddell $\mathrm{P}$, Eaton $\mathrm{D}$, Millar $\mathrm{AB}$, et al. Underestimating treatment benefit of lung transplantation for idiopathic pulmonary fibrosis. BMJ 2014; 348: g24.

25 Valeyre D. Towards a better diagnosis of idiopathic pulmonary fibrosis. Eur Respir Rev 2011; 20: 108-113.

26 Danoff SK, Schonhoft EH. Role of support measures and palliative care. Curr Opin Pulm Med 2013; 19: 480-484.

27 British Lung Foundation. IPF report: lost in the system. www.blf.org.uk/Page/IPF-report-Lost-in-the-System Date last updated: 2015. Date last accessed: July 14, 2015

28 British Lung Foundation. IPF Patient Charter. www.blf.org.uk/Page/IPF-patient-charter Date last updated: 2015. Date last accessed: July 14, 2015.

29 Bartlett SJ, Barnes T, McIvor RA. Integrating patients into meaningful real-world research. Ann Am Thorac Soc 2014; 11: Suppl. 2, S112-S117.

30 Reimann A, Bend J, Dembski B. Patientenzentrierte Versorgung bei seltenen Erkrankungen. Perspektive von Patientenorganisationen [Patient-centred care in rare diseases. A patient organisations' perspective]. Bundesgesundheitsblatt Gesundheitsforschung Gesundheitsschutz 2007; 50: 1484-1493.

31 Chen DS, Locarnini S, Wait S, et al. Report from a Viral Hepatitis Policy Forum on implementing the WHO Framework for Global Action on viral hepatitis in North Asia. J Hepatol 2013; 59: 1073-1080.

32 FitzSimons DW. Prevention and control of viral hepatitis: the role and impact of patient and advocacy groups in and outside Europe. Vaccine 2008; 26: 5669-5674.

33 Vogel L. Patient charters: the provincial experience. CMAJ 2010; 182: E639-E640. 